\title{
Hjerte, smerte - kardiovaskulær sikkerhet og ikke-steroide antiinflammatoriske midler
}

\begin{abstract}
BAKGRUNN Den selektive syklooksygenase (COX)-2 hemmeren rofekoksib ble trukket fra markedet i 2004 på grunn av kardiovaskulær toksisitet. Vi har evaluert data om kardiovaskulære bivirkninger forårsaket både av COX-2-hemmere og andre ikke-steroide antiinflammatoriske midler (NSAID-midler) etter 2004.
\end{abstract}

KUNNSKAPSGRUNNLAG Søk i PubMed for perioden 2004-14 identifiserte 243 relevante artikler. Etter en påfølgende seleksjonsprosess ble 63 artikler gjennomgått og evaluert i lys av norsk praksis.

RESULTATER Resultatene fra de gjennomgåtte studiene er ikke entydige. En overvekt av data tyder på at samtlige selektive COX-2-hemmere, diklofenak og høydose ibuprofen gir kardiovaskulære bivirkninger av problematisk omfang, mens naproksen gjennomgående oppviser lav eller fraværende risiko. For de fleste ikke-steroide antiinflammatoriske midler er høy dose relatert til økt risiko, og risikoøkningen ser ut til å være til stede fra behandlingsstart. Effekten av behandlingsvarighet og predisposisjon for kardiovaskulær sykdom er mer omstridt.

FORTOLKNING Kardiovaskulære bivirkninger fremstår som en gruppeeffekt som gjelder samtlige undersøkte ikke-steroide antiinflammatoriske midler unntatt naproksen og lavdose ibuprofen. Den tradisjonelle inndelingen i COX-2-selektive og ikke-selektive midler er uegnet for risikostratifisering. Dagens forbruksmønster av ikke-steroide antiinflammatoriske midler i befolkningen samsvarer ikke med vår viten om den risikoøkning pasientene utsettes for.

Den selektive syklooksygenase (COX)-2hemmeren rofekoksib ble trukket fra verdensmarkedet i 2004 av produsenten etter lengre tids bekymring for at både dette midlet og andre av de da nylig introduserte COX-2-hemmerne hadde alvorlige kardiovaskulære bivirkninger. En sentral mekanisme bak dette er antatt å være at hemmingen av COX-2 gir nedsatt produksjon av prostasyklin, som er viktig for normal endotelfunksjon i blodkar (1).

I ettertid er ikke bare de selektive COX-2hemmerne, men også andre ikke-steroide antiinflammatoriske midler (NSAID-midler), kommet i søkelyset mistenkt for å forårsake tromboemboliske hendelser som kan føre til alvorlige kardiovaskulære bivirkninger (hjerteinfarkt, hjerneslag, plutselig død m.m.). De sentrale forskningsspørsmålene, som vil bli diskutert her, kan oppsummeres som følger:

- Er økt kardiovaskulær risiko en effekt som gjelder alle COX-2-hemmere?

- Er det en tilsvarende økt risiko for kardiovaskulære hendelser når det gjelder andre ikke-steroide antiinflammatoriske midler?

- Hvor stor er risikoøkningen?

- Modifiseres risikoen av dose, behandlingsvarighet og kardiovaskulær bakgrunnsrisiko?

Forbruket av ikke-steroide antiinflammatoriske midler i Norge i 2013 var på nær 43 definerte døgndoser (DDD) per 1000 innbyg- gere per døgn, hvorav selektive COX-2hemmere utgjorde $6,8 \%$ (2). Refusjonsordninger og markedsføringsstatus, som begge innvirker på forbruksmønsteret, er endret for COX-2-hemmerne det siste tiåret. Kombinasjonen av utbredt bruk og gjenopprettet refusjonsstatus for noen COX-2-hemmere (tab 1) aktualiserer spørsmålet om sikkerheten til alle legemidler i gruppen ikkesteroide antiinflammatoriske midler.

\section{Kunnskapsgrunnlag}

Studien er basert på søk i PubMed for perioden fra og med 2004 og frem til mai 2014 med følgende søkestreng: «anti-inflammatory agents, non-steroidal/adverse effects»[Mesh Terms] OR «naproxen/adverse effects»[Mesh Terms]) OR «ibuprofen/adverse effects»[Mesh Terms]) OR «diclofenac/adverse effects»[Mesh Terms]) AND «cardiovascular diseases/chemically induced»[Mesh Terms]) AND («risk»[MeSH Terms] OR «risk»[All Fields]) AND (Meta-Analysis[ptyp] OR Review[ptyp] OR systematic[sb]) AND («2004/ 01/01»[PDAT] : «2014/05/31»[PDAT]) AND «humans»[MeSH Terms].

Dette ga totalt 243 artikler. En påfølgende eksklusjonsprosess ut fra forhåndsdefinerte kriterier reduserte antallet til 51. Etter gjennomgang av disse artiklenes referanselister ble ytterligere 12 artikler inkludert. Denne oversikten er basert på disse 63 artiklene, som er vurdert i relasjon til annen litteratur

\author{
Marie Viel Møllersen \\ Helle Norgård \\ Olav Spigset \\ Lars Slørdal \\ lars.slordal@ntnu.no \\ Institutt for laboratoriemedisin \\ barne- og kvinnesykdommer \\ Norges teknisk-naturvitenskapelige universitet \\ og \\ Avdeling for klinisk farmakologi
}

Marie Viel Møllersen og Helle Norgård har bidratt i like stor grad til denne artikkelen.

Artikkelen er basert på en studentoppgave ved Norges teknisk-naturvitenskapelige universitet.

Se også kunnskapsprøve på www.tidsskriftet.no/quiz

\section{HOVEDBUDSKAP}

Bruk av selektive COX-2-hemmere, diklofenak og høye doser ibuprofen er assosiert med økt risiko for kardiovaskulære hendelser

En slik risikoøkning er ikke vist for naproksen

Det relativt høye forbruket av kardiotoksiske ikke-steroide antiinflammatoriske midler i Norge bør reduseres 
Tabell 1 Omsetning og refusjonsstatus for ikke-steroide antiinflammatoriske midler i Norge i 2013

\begin{tabular}{|c|c|c|}
\hline Legemiddel (salgsnavn) & Omsetning i $2013^{1}$ & Markedsførings- og refusjonsstatus \\
\hline Rofekoksib (Vioxx) & - & Avregistert i 2004 \\
\hline Etorikoksib (Arcoxia) & 2,11 & $\begin{array}{l}\text { Forhåndsgodkjenning trukket tilbake i 2005, fra } 2008 \text { refusjon ved palliasjon i livets } \\
\text { sluttfase, fra } 2012 \text { ved kroniske sterke smerter, artrose og artritt, fra } 2014 \text { ved bivirk- } \\
\text { ninger av tuberkuloseterapi }\end{array}$ \\
\hline Valdekoksib (Bextra) & - & Avregistert i 2005 \\
\hline Parekoksib (Dynastat) & 0,01 & $\begin{array}{l}\text { Markedsføres, men har ikke forhåndsgodkjent refusjon. Indisert ved korttidsbehand- } \\
\text { ling av postoperativ smerte hos voksne }\end{array}$ \\
\hline Celekoksib (Celebra, Celebrex) & 0,80 & $\begin{array}{l}\text { Forhåndsgodkjenning trukket tilbake i 2005, fra } 2008 \text { refusjon ved palliasjon i livets } \\
\text { sluttfase, fra } 2013 \text { ved kroniske sterke smerter, artrose og artritt, fra } 2014 \text { ved bivirk- } \\
\text { ninger av tuberkuloseterapi }\end{array}$ \\
\hline Naproksen (mange) & 3,77 & $\begin{array}{l}\text { Refusjonsberettiget bruk: Palliasjon i livets sluttfase, kroniske sterke smerter, } \\
\text { artrose, artritt, bivirkninger av tuberkuloseterapi, urinsyregikt }\end{array}$ \\
\hline Diklofenak (mange) & 10,13 & $\begin{array}{l}\text { Refusjonsberettiget bruk: Palliasjon i livets sluttfase, kroniske sterke smerter, } \\
\text { artrose, artritt, bivirkninger av tuberkuloseterapi, urinsyregikt }\end{array}$ \\
\hline Ibuprofen (mange) & 17,70 & $\begin{array}{l}\text { Refusjonsberettiget bruk: Palliasjon i livets sluttfase, kroniske sterke smerter, } \\
\text { artrose, artritt, bivirkninger av tuberkuloseterapi, urinsyregikt }\end{array}$ \\
\hline
\end{tabular}

${ }^{1}$ Målt i definerte døgndoser (DDD) per 1000 innbyggere per døgn (2)

om forbruk, refusjon og anbefalinger knyttet til disse legemidlene i Norge.

\section{Rofekoksib}

I analyser fra de nærmeste årene etter avregistrering ble det påvist en signifikant og doseavhengig risikoøkning for kardiovaskulære hendelser ved bruk av rofekoksib, med en relativ risiko (RR) i området $1,25-2,19(3,4)$.

Risikoøkningen ble bekreftet $\mathrm{i}$ en systematisk litteraturgjennomgang av observasjonsstudier fra tidsrommet 1990-2008 med vekt på ikke-steroide antiinflammatoriske midler og slagrisiko (5) og i en metaanalyse (6). Det foreløpig siste bidraget kom i 2011 med McGettigan \& Henrys systematiske gjennomgang av 30 pasient-kontroll-studier og 21 kohortstudier, som også ga liknende resultater (7) (tab 2).

\section{Etorikoksib}

Etorikoksib omsettes i betydelig omfang i Norge (tab 1). En systematisk oversikt og metaanalyse fra 2005 (8) viste at bruk innebar en mulig økt risiko for tromboemboliske hendelser, med en oddsratio (OR) på 1,49 og et $95 \%$ konfidensintervall $(\mathrm{KI})$ på $0,42-5,31$. En systematisk oversikt fra 2007 (4) understøtter dette.

I Trelle og medarbeideres nettverksmetaanalyse av randomiserte studier fra 2011 (9) var det økt risiko for kardiovaskulær død ved bruk av etorikoksib (RR 4,07; $95 \% \mathrm{KI}$ 1,23-15,7), men ingen økt risiko for hjerteinfarkt, slag eller andre kardiovaskulære hendelser. I parvise sammenlikninger fant McGettigan \& Henry (7) at etorikoksib ga økt kardiovaskulær risiko (RR 2,05; 95 \% KI 1,45-2,88).

\section{Valdekoksib og parekoksib}

Selv om markedsføringstillatelsen for parekoksibs morsubstans (prodrug) valdekoksib ble trukket tilbake i 2005 , er den aktive metabolitten parekoksib fortsatt i bruk (tab 1).

I en metaanalyse fra 2005 (10) ble tre studier inkludert der valdekoksib ble gitt intravenøst like etter kirurgi, med påfølgende behandling med peroralt parekoksib i $10-14$ dager. Resultatene viste en signifikant økt risiko for alvorlige kardiovaskulære hendelser ved bruk av disse to koksibene sammenliknet med placebo (OR 2,3; $95 \% \mathrm{KI} 1,1-4,7$ ). McGettigan \& Henry (7) fant derimot ingen $ø$ kt risiko for kardiovaskulære hendelser ved bruk av valdekoksib i sin metaanalyse.

\section{Celekoksib}

Celekoksib brukes i betydelig og økende grad (tab 1) (2). I 2005 rapporterte Solomon og medarbeidere forekomsten av potensielle alvorlige kardiovaskulære hendelser blant 2035 pasienter i APC-studien (Adenoma Prevention with Celecoxib) (11). Sju av 679 pasienter $(1,0 \%)$ som var randomisert til placebo opplevde alvorlige kardiovaskulære hendelser, mot 16 av de 685 pasientene $(2,3 \%)$ som fikk $200 \mathrm{mg}$ celekoksib to ganger daglig (hasardratio (HR) 2,3; $95 \% \mathrm{KI}$ $0,9-5,5)$ og 23 av de 671 pasientene $(3,4 \%)$ som fikk $400 \mathrm{mg}$ celekoksib to ganger daglig (HR 3,4; $95 \%$ KI 1,4-7,8) (11).

På bakgrunn av disse funnene ble studien avsluttet tidligere enn planlagt. Resultatene fra en tilsvarende studie med rofekoksib (12) var etter alt å dømme den utløsende årsaken til at produsenten trakk midlet fra verdensmarkedet høsten 2004.

Caldwell og medarbeideres systematiske gjennomgang fra 2006 viste at det var økt risiko for hjerteinfarkt ved bruk av celekoksib, med en oddsratio som, avhengig av datagrunnlaget, varierte fra $1,88(95 \% \mathrm{KI}$ $1,15-3,08)$ til $2,26(95 \% \mathrm{KI} 1,0-5,1)(13)$.

I motsetning til dette viste en metaanalyse av White og medarbeidere fra 2007 ingen økt risiko for kardiovaskulære hendelser etter bruk av celekoksib sammenliknet med placebo eller tradisjonelle ikke-steroide antiinflammatoriske midler (14). Kriteriene for inklusjon i denne samleanalysen var at data blant annet skulle være fra celekoksibprodusenten Pfizers egen database og publisert før oktober 2004. Dette innebar eksklusjon av tre sentrale placebokontrollerte langtidsstudier av midlets sikkerhet-APC-studien, PreSAP-studien (Prevention of Sporadic Adenomatous Polyps) og ADAPT-studien (Alzheimer's Disease Antiinflammatory Prevention Trial) $(11,15,16)$. Disse tre studiene ble alle avsluttet tidligere enn planlagt på grunn av økt forekomst av kardiovaskulære komplikasjoner i celekoksibgruppen i APC-studien. White og medarbeideres analyse (14) inkluderer på den annen side mange studier av kort varighet og/ eller med få deltakere (hvor bivirkningsfrekvensen blir lav) og mange studier med komparatoren diklofenak (se under).

I 2008 gjorde Solomon og medarbeidere (17) en samleanalyse av seks placebokontrollerte studier der man evaluerte risikoen for 
Tabell 2 Relativ risikoøkning for kardiovaskulære hendelser etter lave og høye doser av utvalgte ikke-steroide antiinflammatoriske midler. Tallene er hentet fra McGettigan \& Henrys systematiske analyse fra 2011 (7)

\begin{tabular}{|c|c|c|}
\hline Legemiddel, definisjon av lavdose/høydose & $\begin{array}{l}\text { Lavdose } \\
\operatorname{RR}(95 \% \mathrm{KI})\end{array}$ & $\begin{array}{l}\text { Høydose } \\
\operatorname{RR}(95 \% \mathrm{KI})\end{array}$ \\
\hline $\begin{array}{l}\text { Rofekoksib } \\
\leq />25 \mathrm{mg} / \mathrm{dag}\end{array}$ & $1,37(1,20-1,57)$ & $2,17(1,59-2,97)$ \\
\hline $\begin{array}{l}\text { Celekoksib } \\
\leq />200 \mathrm{mg} / \mathrm{dag}\end{array}$ & $1,26(1,09-1,47)$ & $1,69(1,11-2,57)$ \\
\hline $\begin{array}{l}\text { Diklofenak } \\
\leq />100 / 150 \mathrm{mg} / \mathrm{dag}^{1}\end{array}$ & $1,22(1,12-1,33)$ & $1,98(1,40-2,82)$ \\
\hline $\begin{array}{l}\text { Ibuprofen } \\
\leq />1200 / 1600 / 1800 \mathrm{mg} / \mathrm{dag}^{1}\end{array}$ & $1,05(0,96-1,15)$ & $1,78(1,35-2,34)$ \\
\hline $\begin{array}{l}\text { Naproksen } \\
\leq />500 / 750 / 1000 \mathrm{mg} / \mathrm{dag}^{1}\end{array}$ & $0,97(0,87-1,08)$ & $1,05(0,89-1,24)$ \\
\hline
\end{tabular}

1 Varierte i de ulike studiene

kardiovaskulær død, hjerteinfarkt, slag, hjertesvikt og tromboemboliske hendelser. Resultatene viste en doseavhengig risikoøkning som var lavest ved bruk av $400 \mathrm{mg}$ per dag (HR $1,1 ; 95 \% \mathrm{KI} 0,6-2,0)$ og signifikant økt ved bruk av $400 \mathrm{mg}$ to ganger daglig (HR 3,1; $95 \%$ KI 1,5-6,1). Studien til McGettingan \& Henry (7) viser liknende resultater (tab 2).

\section{Naproksen}

Sammenliknet med andre klassiske ikkesteroide antiinflammatoriske midler er forbruket av naproksen i Norge lavt (tab 1). Studien til McGettingan \& Henry (7) viser at midlet innebærer lavere risiko for kardiovaskulære hendelser enn de andre ikke-steroide antiinflammatoriske midlene (tab 2). Dette bekreftes av andre (6). Det er fremdeles knyttet noe usikkerhet til funnene - det spekuleres blant annet i hvorvidt lave/reseptfrie doser av naproksen påvirker den kardiovaskulære risikoen og hvordan spesielt langtidsbehandling kan ha uheldige følger i form av gastrointestinale bivirkninger $(6,7)$.

Naproksen og lavdose ibuprofen er de eneste ikke-steroide antiinflammatoriske midler som i terapeutiske konsentrasjoner blokkerer de to COX-isoenzymene i tilnærmet like stor grad, og som dermed kan tenkes å ha en kardioprotektiv effekt som likner den acetylsalisylsyre har (18). Naproksen $500 \mathrm{mg}$ to ganger daglig gir en hemming av COX-1 som er omfattende og langvarig nok til å gi platehemming og dermed teoretisk balansere den økte kardiovaskulære risikoen sekundært til COX-2-hemming og påfølgende nedsatt prostasyklinproduksjon (19).

Teorien om at naproksen har en kardioprotektiv effekt ble blant annet brukt til å forklare forskjellen i kardiovaskulære hendelser mellom naproksen og rofekoksib i VIGOR-studien (Vioxx Gastrointestinal Outcomes Re- search) (20). Jüni og medarbeidere (21), som har ettergått hypotesen, har konkludert med at hvis naproksen har en kardioprotektiv effekt, er den $i$ beste fall liten og ingen gangbar forklaring på overhyppigheten av kardiovaskulære hendelser i rofekoksibgruppen i VIGORstudien. Senere har verken Kearney og medarbeidere (22) eller McGettigan \& Henry (3) funnet holdepunkter for kardioprotektive effekter ved bruk av naproksen. Andre analyser kan på den annen side tyde på at naproksen har en viss kardioprotektiv effekt $(23,24)$.

\section{Diklofenak}

Diklofenak er i utbredt bruk i Norge (tab 1). De aller fleste studier, både randomiserte, kontrollerte undersøkelser $(6,9,22)$ og observasjonsstudier $(3,7)$, viser at diklofenak har den høyeste kardiovaskulære risikoen blant tradisjonelle ikke-steroide antiinflammatoriske midler, og at risikoen tilsvarer den som utløses ved bruk av selektive COX-2hemmere $(6,7)$ (tab 2). Diklofenak er tradisjonelt blitt sett på som et ikke-selektivt ikkesteroid antiinflammatorisk middel. Diklofenak har imidlertid en COX-2-selektivitet som ligger tett opp mot den hos celekoksib $(25,26)$, og kan betraktes som en selektiv COX-2-hemmer $(1,27)$.

Tradisjonelt har man tildelt de to gruppene ikke-steroide antiinflammatoriske midler ulike bivirkningsprofiler - de ikkeselektive gir først og fremst gastrointestinale bivirkninger, mens de selektive COX-2hemmerne gir tromboemboliske bivirkninger. På bakgrunn av denne antakelsen knyttet det felleseuropeiske legemiddelverket EMA (European Medicines Agency) koksibene til sterkere advarsler og kontraindikasjoner angående tromboembolisk risiko enn tradisjonelle ikke-steroide antiinflammatoriske midler. Siden diklofenak oppviser likhetstrekk med koksibene, kan en slik inndeling være både misvisende og uheldig (28). I ettertid har imidlertid diklofenak fått advarsler tilsvarende koksibene av EMA og Statens legemiddelverk (29), selv om midlet fremdeles omtales som et ikke-selektivt ikke-steroid antiinflammatorisk middel.

Det er vist økt kardiovaskulær risiko ved lave doser diklofenak (100 mg/dag). Denne doseringen ligger nær opp til den maksimale anbefalte reseptfrie dosen $(75 \mathrm{mg} / \mathrm{dag})$, noe som aktualiserer spørsmålet om hvorvidt omsetningen bør reguleres strengere (7). Etter at EMA oppjusterte advarslene om kardiovaskulær risiko ved bruk av diklofenak tilsvarende koksibene, ble også den reseptfrie bruken $\mathrm{i}$ Norge anbefalt innskjerpet (30), i tråd med anbefalingene til McGettigan \& Henry (7).

\section{Ibuprofen}

Ibuprofen er det mest solgte ikke-steroide antiinflammatoriske midlet i Norge (tab 1). I motsetning til hva som er sett med naproksen og diklofenak, viser studier at det først ved doser over $1200 \mathrm{mg} /$ dag er økt kardiovaskulær risiko $(7,18)(\operatorname{tab} 2)$.

Til tross for at flere studier indikerer at risikoen ved ibuprofen og naproksen er forskjellig, er disse to medikamentene (sammen med de øvrige tradisjonelle ikke-steroide antiinflammatoriske midlene, med unntak av diklofenak) knyttet opp mot de samme advarsler og kontraindikasjoner for kardiovaskulær risiko. Analysene indikerer imidlertid at ibuprofen risikomessig befinner seg i et mellomsjikt mellom naproksen og diklofenak. Ibuprofentabletter med styrke på inntil $400 \mathrm{mg}$ og med anbefalinger om maksimaldoser på inntil $1600 \mathrm{mg}$ daglig selges reseptfritt i Norge, og ibuprofen er det eneste reseptfrie ikke-steroide antiinflammatoriske midlet som kan kjøpes andre steder enn på apotek.

\section{Er risikoen avhengig av dose, behandlingsvarighet eller andre faktorer?}

De fleste som har undersøkt mulige sammenhenger mellom dose ikke-steroid antiinflammatorisk middel og økt risiko for kardiovaskulære hendelser, har påvist en dose-effektsammenheng $(7,13,17,18,31)$. Unntaket er naproksen, hvor risikoøkningen har vært fraværende (tab 2), og en metaanalyse (6) der man ikke kunne påvise at den vaskulære risikoen til verken selektive COX-2-hemmere eller tradisjonelle ikke-steroide antiinflammatoriske midler var doseavhengig.

McGettigan \& Henry (7) påviste økt risiko for kardiovaskulære hendelser i løpet av den første måneden ved bruk av noen ikkesteroide antiinflammatoriske preparater. De identifiserte 12 studier der slike hendelser hos nye brukere av slike midler var rapportert. Ni av disse studiene viste at den kardio- 
vaskulære risikoen økte innen de første 30 dagene ved bruk av celekoksib, rofekoksib, ibuprofen og diklofenak. I tre av studiene var det også økt risiko innen 14 dager.

En dansk kohortstudie støtter denne konklusjonen. Schjerning Olsen og medarbeidere (32) undersøkte varigheten av behandling med ikke-steroide antiinflammatoriske midler og kardiovaskulær risiko hos pasienter som tidligere hadde hatt hjerteinfarkt. De konkluderte med at selv kortvarig behandling var assosiert med økt risiko for $\mathrm{d} ø \mathrm{~d} /$ reinfarkt - for rofekoksib var risikoen økt allerede etter 7-14 dagers bruk, for celekoksib etter 14-30 dager, for ibuprofen etter sju dager og for diklofenak allerede fra starten av behandlingen.

Andre som har studert tidsrelasjonene har kommet til noe forskjellige resultater $(18,33)$ eller har vært ute av stand til å påvise distinkte tidsrelasjoner for risikoutvikling $(6,33)$. En overvekt av data tyder imidlertid på at risikoen er til stede fra behandlingsstart.

Intervensjonsgruppene $\mathrm{i}$ de fleste studiene av den kardiovaskulære sikkerhetsprofilen til ikke-steroide antiinflammatoriske midler har vært pasienter med kroniske inflammatoriske og revmatiske sykdommer. En sentral indikasjon for behandling med disse midlene er nettopp slike sykdommer. Til tross for dette bruker de fleste pasienter midlene på grunn av andre og mer trivielle årsaker, som hodepine og muskel- og skjelettsmerter. Det er derfor blitt stilt spørsmål om den kardiovaskulære risikoen indusert av disse midlene også er økt i den generelle befolkningen (34).

McGettigan \& Henry (7) prøvde å svare på dette spørsmålet i sin metaanalyse. De kategoriserte de inkluderte studiene basert på utgangsrisiko for kardiovaskulær sykdom - høyrisikopasientene hadde tidligere vært utsatt for vaskulære iskemiske hendelser, mens man for lavrisikogruppen ikke hadde anamnestiske opplysninger om slike hendelser. De fant ingen gjennomgående forskjell $\mathrm{i}$ risikoestimatene $\mathrm{i}$ forhold til underliggende risiko for hjerte- og karsykdommer (7), noe som betyr at lavrisikoindivider er utsatt for den samme proporsjonale økningen i sannsynlighet for en kardiovaskulær hendelse som de med høy risiko, men at totalt økt risiko vil være lavere.

En annen metaanalyse (6) konkluderte med det samme - den proporsjonale effekten på kardiovaskulære hendelser var den samme, uavhengig av bakgrunnsrisiko. I motsetning til dette viste Solomon og medarbeidere (17) i sin metaanalyse med celekoksib at også den relative risikoen var høyere hos individer med en allerede etablert risiko for hjerte- og karsykdommer. Andre som har undersøkt dette, har også kommet frem til at den relative risikoøkningen er større hos pasienter med en i utgangspunktet forhøyet risiko for kardiovaskulære hendelser $(18,31)$.

\section{Konklusjon}

Analysene som ligger til grunn for vår gjennomgang, lar seg vanskelig syntetisere - de bruker ulike endepunkter og statistiske metoder og er i varierende grad basert på de samme primærkildene. De ikke-steroide antiinflammatoriske midlene er en heterogen gruppe når det gjelder risiko for kardiovaskulære hendelser.

Flere studier indikerer at naproksen ikke er assosiert med økt risiko, uansett dose. Når det gjelder diklofenak, celekoksib og andre selektive COX-2-hemmere, er det derimot $ø \mathrm{kt}$ risiko for alle doser. Ibuprofen assosieres med økt risiko ved høye doser. Den økte risikoen kan ikke tallfestes nøyaktig, men tilsvarer omtrent en fordobling av antall hjerteinfarkter sammenliknet med bakgrunnsrisikoen hos brukere av diklofenak, selektive COX-2-hemmere eller høydose ibuprofen.

Risikoen ser ut til å være økt fra behandlingsstart. Hvorvidt risikoøkningen er proporsjonal uansett kardiovaskulær bakgrunnsrisiko, er mer usikkert. Siden eldre har en høyere bakgrunnsrisiko for kardiovaskulær sykdom enn yngre, vil den absolutte risikoen uansett være særlig høy ved behandling av eldre pasienter. Foreliggende kunnskap tilsier at man både bør tilstrebe å redusere forbruket av ikke-steroide antiinflammatoriske midler i befolkningen som helhet og å styre bruken bort fra de kardiotoksiske midlene i denne legemiddelgruppen.

\section{Marie Viel Møllersen (f. 1990)}

er medisinstudent ved Norges teknisk-naturvitenskapelige universitet.

Forfatter har fylt ut ICMJE-skjemaet og oppgir ingen interessekonflikter.

\section{Helle Norgård (f. 1990)}

er medisinstudent ved Norges teknisk-naturvitenskapelige universitet.

Forfatter har fylt ut ICMJE-skjemaet og oppgir ingen interessekonflikter.

\section{Olav Spigset (f. 1963)}

er spesialist i klinisk farmakologi, overlege og professor.

Forfatter har fylt ut ICMJE-skjemaet og oppgir ingen interessekonflikter.

\section{Lars Slørdal (f. 1955)}

er spesialist i klinisk farmakologi, professor og overlege.

Forfatter har fylt ut ICMJE-skjemaet og oppgir ingen interessekonflikter.
Litteratur

Evensen S, Spigset O, Slørdal L. COX-2-hemmer - ett skritt frem og to tilbake. Tidsskr Nor Lægeforen 2005; 125 : 875-8

2. Folkehelseinstituttet. Legemiddelforbruket i Norge ATC gruppe M, 2014. www.legemiddelforbruk.no/ (4.5.2014).

3. McGettigan P. Henry D. Cardiovascular risk and inhibition of cyclooxygenase: a systematic review of the observational studies of selective and nonselective inhibitors of cyclooxygenase 2. JAMA 2006: 296: 1633-44.

4. Scott PA, Kingsley GH, Smith CM et al. Non-steroidal anti-inflammatory drugs and myocardial infarctions: comparative systematic review of evidence from observational studies and randomised controlled trials. Ann Rheum Dis 2007: 66 : 1296-304.

5. Varas-Lorenzo C, Riera-Guardia N, Calingaert B et al. Stroke risk and NSAIDs: a systematic review of observational studies. Pharmacoepidemiol Drug Saf 2011; 20: 1225-36.

6. Bhala N, Emberson J, Merhi A et al. Vascular and upper gastrointestinal effects of non-steroidal anti-inflammatory drugs: meta-analyses of individual participant data from randomised trials. Lancet 2013; 382: 769-79.

7. McGettigan P. Henry D. Cardiovascular risk with non-steroidal anti-inflammatory drugs: systematic review of population-based controlled observational studies. PLoS Med 2011; 8: e1001098.

8. Aldington S, Shirtcliffe P. Weatherall M et al. Systematic review and meta-analysis of the risk of major cardiovascular events with etoricoxib therapy. N Z Med J 2005; 118: U1684.

9. Trelle S, Reichenbach S, Wandel S et al. Cardiovascular safety of non-steroidal anti-inflammatory drugs: network meta-analysis. BMJ 2011; 342: c7086.

10. Aldington S, Shirtcliffe P. Weatherall M et al. Increased risk of cardiovascular events with pare coxib/valdecoxib: a systematic review and metaanalysis. N Z Med J 2005; 118: U1755.

11. Solomon SD, McMurray JJ, Pfeffer MA et al. Cardiovascular risk associated with celecoxib in a clinical trial for colorectal adenoma prevention. N Engl J Med 2005; 352: 1071-80.

12. Bresalier RS Sandler RS, Quan H et al Cardiovascular events associated with rofecoxib in colorectal adenoma chemoprevention trial. N Engl J Med 2005; 352: 1092-102

13. Caldwell B, Aldington S, Weatherall M et al. Risk of cardiovascular events and celecoxib: a systematic review and meta-analysis. J R Soc Med 2006; 99: $132-40$

14. White WB, West CR, Borer JS et al. Risk of cardiovascular events in patients receiving celecoxib: a meta-analysis of randomized clinical trials. Am J Cardiol 2007; 99: $91-8$

15. ADAPT Research Group. Cardiovascular and cere brovascular events in the randomized, controlled Alzheimer's Disease Anti-Inflammatory Prevention Trial (ADAPT). PLoS Clin Trials 2006: 1: e33.

16. Arber N, Eagle CJ, Spicak J et al. Celecoxib for the prevention of colorectal adenomatous polyps. N Engl J Med 2006; 355: 885-95.

17. Solomon SD, Wittes J, Finn PV et al. Cardiovascular risk of celecoxib in 6 randomized placebocontrolled trials: the cross trial safety analysis. Circulation 2008; 117: 2104-13.

18. García Rodríguez LA, Tacconelli S, Patrignani P. Role of dose potency in the prediction of risk of myocardial infarction associated with nonsteroidal anti-inflammatory drugs in the general population. J Am Coll Cardiol 2008; 52: 1628-36

19. Capone ML, Tacconelli S, Sciulli MG et al. Clinical pharmacology of platelet, monocyte, and vascular cyclooxygenase inhibition by naproxen and lowdose aspirin in healthy subjects. Circulation 2004 109: 1468-71

20. Bombardier C, Laine L, Reicin A et al. Comparison of upper gastrointestinal toxicity of rofecoxib and naproxen in patients with rheumatoid arthritis. N Engl J Med 2000; 343: 1520-8. 
21. Jüni P, Nartey L, Reichenbach $S$ et al. Risk of cardiovascular events and rofecoxib: cumulative meta-analysis. Lancet 2004: 364: 2021 -9.

22. Kearney PM, Baigent C, Godwin J et al. Do selective cyclo-oxygenase- 2 inhibitors and traditional non-steroidal anti-inflammatory drugs increase the risk of atherothrombosis? Meta-analysis of randomised trials. BMJ 2006; 332: 1302-8.

23. Hernández-Díaz S, Varas-Lorenzo C, García Rodríguez LA. Non-steroidal antiinflammatory drugs and the risk of acute myocardial infarction. Basic Clin Pharmacol Toxicol 2006; 98: 266-74.

24. Matchaba P, Gitton X, Krammer G et al. Cardiovascular safety of lumiracoxib: a meta-analysis of all randomized controlled trials $>$ or $=1$ week and up to 1 year in duration of patients with osteoarthritis and rheumatoid arthritis. Clin Ther 2005; 27: 1196-214.

25. Chan CC, Boyce S, Brideau C et al. Rofecoxib [Vioxx, MK-0966; 4-(4'-methylsulfonylphenyl)-3phenyl-2-(5H)-furanone]: a potent and orally active cyclooxygenase-2 inhibitor. Pharmacological and biochemical profiles. J Pharmacol Exp Ther 1999; 290: $551-60$.

26. Riendeau D, Percival MD, Brideau $C$ et al. Etoricoxib (MK-0663): preclinical profile and comparison with other agents that selectively inhibit cyclooxygenase-2. J Pharmacol Exp Ther 2001; 296: $558-66$.

27. Waksman JC, Brody A, Phillips SD. Nonselective nonsteroidal antiinflammatory drugs and cardiovascular risk: are they safe? Ann Pharmacother 2007; 41: 1163-73.

28. Krötz F. Struthmann L. A Review on the risk of myocardial infarction associated with the NSAID diclofenac. Cardiovasc Hematol Disord Drug Targets 2010; 10: 53-65.

29. Legemiddelverket. Nye anbefalinger for diklofenak. www.legemiddelverket.no/Nyheter/ Bivirkninger/Sider/Nye-anbefalinger-fordiklofenak.aspx (21.5.2014).

30. Legemiddelverket. Nye vilkår for reseptfri diklofenak. www.legemiddelverket.no/Nyheter/ Bivirkninger/Sider/Nye-vilk\%C3\%A5r-forreseptfri-diklofenak.aspx (10.1.1015)

31. Varas-Lorenzo C, Riera-Guardia N, Calingaert B et al. Myocardial infarction and individual nonsteroidal anti-inflammatory drugs meta-analysis of observational studies. Pharmacoepidemiol Drug Saf 2013; 22: $559-70$.

32. Schjerning Olsen AM, Fosbøl EL, Lindhardsen J et al. Duration of treatment with nonsteroidal antiinflammatory drugs and impact on risk of death and recurrent myocardial infarction in patients with prior myocardial infarction: a nationwide cohort study. Circulation 2011: 123: 2226-35

33. Lévesque LE, Brophy JM, Zhang B. Time variations in the risk of myocardial infarction among elderly users of COX-2 inhibitors. CMAJ 2006; 174 $1563-9$

34. Fosbøl EL, Køber L, Torp-Pedersen C et al. Cardiovascular safety of non-steroidal anti-inflammatory drugs among healthy individuals. Expert Opin Drug Saf 2010; 9: 893-903.

Mottatt 14.10. 2014, første revisjon innsendt 15.1. 2015, godkjent 26.1. 2015. Redaktør: Are Brean. 